\title{
Instrument Technology Support in the Teaching of Synthetic Economic Disciplines
}

\author{
Seda Khachaturova ${ }^{1, a}$, Tamara Shikhnabieva ${ }^{2, b}$, Anna Arinushkina ${ }^{2, c *}$, \\ 1 Plekhanov Russian University of Economics, 117997, 36 Stremyanny lane, Moscow, Russia \\ 2 Institute of Education Management of the Russian Academy of Education, 105062, 16 \\ Zhukovskogo str., Moscow, Russia \\ aseda_@mail.ru, bshetoma@mail.ru, canna.arin@mail.ru \\ ${ }^{*}$ Corresponding author
}

Keywords: problems of education, instrumental technology, higher education, improving education, online tutorials, training, educational activities, improving the quality of education, synthetic economic disciplines

\begin{abstract}
:
Introduction: The teaching of synthetic disciplines, including information from various subject areas, is analyzed in the paper. Perfecting the process of teaching synthetic disciplines based on the use of specially developed instrumental technologies predetermined the need for this scientific work.

Materials and methods: As a result of the research, issues in teaching the so-called synthetic disciplines, which are constructed at the junction of different subject areas, have been revealed. Qualitative study of modern disciplines requires extensive use of regulatory information, as well as law enforcement practices, comments, etc. The use of software tools and instrumental support technologies that make it possible for a research to be carried out in conjunction with the ability to obtain necessary information (based on hypertext transitions) allows for an increase to the efficiency of the educational process.

Results: The authors attempted to integrate knowledge from different subject areas. The developed algorithms and software, instrumental technologies for creating a series of electronic textbooks for teaching synthetic disciplines based on hypertext access to a data bank make it possible to carry out the teaching of synthetic disciplines, reaching a new standard of quality. In particular, the proposed tool technologies make it possible to increase the efficiency of the educational process and substantially reduce the time required to search for information from various subject areas necessary for the study of synthetic disciplines.

Discussion: The "Programe for the Support of Teaching Synthetic Disciplines" is offered by the authors. It provides a chain of educational processes from creating an electronic textbook by subject teachers, including it into the Teaching System, integrating related areas of knowledge, and obtaining the necessary information support before checking residual knowledge with the use of a test subsystem.
\end{abstract}

Practical significance of the research lies in the effectiveness of using modern instrumental methods, forms and means in teaching synthetic disciplines at a university.

\section{Introduction}

Educational institutions are an integral part of a market economy, providing a constant replenishment of the labor market with specialists of various professions. The main task of universities is the high-quality training of bachelors and masters for various sectors of the economy. The rapid growth of information in all branches and fields of human activity and the need for its aggregation and synthesis introduces certain difficulties and gives rise to the tasks of its target processing by subject teachers for the students in order to properly master subject knowledge.

Based on a study of the teaching process of a number of disciplines in higher education institutions, the authors concluded that traditional textbooks do not keep up with the dynamics of development and changes in the content of Russian legislation and branches of the economy. This situation adversely affects the process of teaching the so-called synthetic disciplines, including information from various fields of 
knowledge. These include, in particular, "Economic Law", "Intellectual Information Systems and Artificial Intelligence Methods in the Economy", "Federal Taxes and Fees", "Labor Economics", "Taxes and Taxation", "Planning and Forecasting in the Economy", etc. In the structure of the above disciplines, a significant place is occupied by regulatory, legislative, reference, statistical information, regulations, and standards. As a result, it acquires the issue of improving existing methods and pedagogical approaches, as well as the use of program-methodical tools and instrumental technologies that facilitate the rapid search, selection, and access to the necessary information in the process of mastering synthetic disciplines, taking into account their content. Operational search for relevant information, which provides the developed software package, allows one to create a synthetic object as a whole and to intensify its development.

\section{Materials and Methods}

The article reflects the results of a qualitatively interpretive study using the authors' academic works as the primary source and the corresponding expert materials as secondary sources, selected by annotated bibliographic and literary review methods; applied qualitative method of analyzing the content and methods of teaching synthetic economic disciplines. An analysis of the pedagogical practice of teaching synthetic disciplines in the system of Russian higher professional education has been carried out. A review of the most relevant foreign academic studies relevant in the context of modifying the content and methods of teaching economic disciplines of synthetic subject areas in the system of higher professional education is also presented in this paper.

The aim of the study is to reassess the results of foreign academic studies that influence the formation of methods of teaching synthetic economic disciplines in the context of analyzing challenges of the Russian pedagogical practice and introducing a software complex that would support teaching of synthetic disciplines developed and tested by the authors of the computer program.

\section{Results}

Currently, information and communication technology tools are firmly established in the education system. As it is known and reflected in the studies of Russian and foreign scientists (Vasyutina, T. L., Stakhno, R. E.) [1], along with traditional teaching aids are widely used electronic tools. The study is important and practical for considering the problem of modifying forms, methods, and the content of the component of synthetic disciplines in the system of Russian higher professional education, which are related to the "way of seeing the world and the practice of scientific research" [2].

In modern Russian and foreign pedagogical scientific literature, research on the integration of subject areas in the teaching of synthetic disciplines in the higher education system is presented from the standpoint of analyzing both various educational practices and pedagogical concepts At the same time, it does not define the vector of "academic convergence" and the implementation of applied research results in teaching practice. This situation has led to the need to generalize and systematize pedagogical results of the research presented in this article.

A number of tasks related to the organization of the database remains an unresolved [3], which is necessary to conduct a high-quality educational process of synthetic disciplines and develop tools for the development of adequate training materials. To solve the above problems, it is proposed to use the developed computer program "Software complex to support the teaching of synthetic disciplines," consisting of:

1. A subsystem interface for creating new electronic textbooks.

2. A Learning System Interface for providing an e-learning course to the user.

The components of the software package meet the following requirements: openness, modularity, compatibility, scalability, reliability, usability, and efficiency (Vasyutina, T. L., Stakhno, R. Ye., 2016 [1]; Khachaturova, S. S., 2016) [4].

Let us highlight the functionality of the "Software support package for teaching synthetic disciplines":

1. The subsystem for the development of electronic textbooks provides a subject teacher with a low labor intensity and a low level of computer literacy, powerful tools for creating training courses 
with the possibility of later loading it into the Teaching system. Subject teachers will be able to take an active part in the process of creating new electronic textbooks on economic synthetic disciplines.

The subsystem interface provides each user with a menu in which a set of tools is presented for selecting and downloading necessary files, saving and automating the creation of a new e-course.

The subsystem's functionality is the provision of a teacher-subject instrumentation to create information about the discipline, theoretical, and practical sections, section for conducting control, intermediate certification, and useful reference books.

At the last stage (creation course), the generation of educational pedagogical material takes place. The generation process is one of the key points of this development. A file being generated is a single file containing all information about a particular electronic course. The file is binary, has a format that is understandable to the software package. A number of instrumental technologies are developed to facilitate an automatic download of the generated file to the training system.

2. The training system provides the user with the necessary theoretical material, a laboratory workshop for sequential training, a convenient system for finding legislative, legal, reference information, key concepts and definitions contained in the course, typical examples of exponentially solved problems/examples.

The defining place in this development is the question of the structure of the Training System, which consists of the three interrelated program-methodical decompositions, united by common goals:

1. Electronic textbooks on economic synthetic disciplines.

2. A legal subsystem.

3. A test subsystem.

Using the training system in the educational process greatly facilitates the access of students to educational and methodological information. The process of learning disciplines and access to legal information occur in parallel. A component of the Teaching system, the test subsystem, allows a teacher to achieve a greater effect, to assess the current level in the development of an academic discipline, to improve the quality of control and reduces the time for conducting classes.

The training system has a specific work algorithm, a procedure for teaching synthetic economic disciplines at the expense of multifunctionality, modularity, continuity, and the possibility of prospective filling with its necessary content.

Let us highlight some technological advantages of the training system: a convenient replication, a timely updating of regulatory, legislative, reference information, a self-study of educational materials by the students, a search for legal information, control of residual knowledge, etc. Each electronic textbook is a system of knowledge that can adapt to changing conditions its component and promoting quality economic education.

The formation of the structure of electronic textbooks is carried out in two aspects:

1. The content structure of electronic textbooks is formed by analogy with the traditional ones: these sections include "Abstract," :Methodical instructions," "Course program," "Lectures," "Typical examples," "Practical work," "Individual tasks," "Test questions," "Recommended literature," "Useful reference book" (in accordance with Fig. 2).

2. The functional part of electronic textbooks describes the implementation of the main functions of the educational process at specific stages of learning. To achieve the goal, the automation of search execution processes in the sections "Lectures and practical work of electronic textbooks" has been developed, which takes over most of the routine operations of organizing the search for regulatory, legislative, reference information in the database of the reference legal subsystem. The developed hypertext integration of the reference-legal subsystem into electronic textbooks contributes to the development of the necessary skills for solving practical economic problems using regulatory, legislative, and reference information. 
One of the most important parts of the "Software support package for teaching synthetic disciplines," which determines its effectiveness in use, is the reference-legal subsystem. It is a complex of automated technologies that ensure the inclusion, storage, updating of legal information and its subsequent use in solving economic problems. Documents are included in the text format from any available sources, starting with thee reference systems "ConsultantPlus" and "Garant" and ending with scanned copies from printed publications. The reference-legal subsystem systematizes documents in accordance with the alphabetic and thematic rubricators by different branches of knowledge. If necessary, outdated documents can be removed from the database. Note that the rubricators can be created by the teachers themselves, taking into account certain specifics of a particular synthetic subject, for the study of which the given Program complex is used.

Searching for the necessary documents is carried out in two ways:

1. By means of the hypertext transition from the sections Practical work and Lectures of the block of electronic textbooks to the reference-legal subsystem. To do this, select a fragment in the text section of the electronic textbook. The highlighted value is automatically converted into hypertext and entered into the search line of the reference legal subsystem.

2. Entering search words directly into the search string of the reference subsystem.

The search for legal documents is carried out according to words included either in the text of the document or in the name of the document. One can also search for documents only in one of the headings. As a result of the search, a list of documents that satisfy the query will be selected, which can be previewed in the reference subsystem window and subsequently opened in the text editor "MS Word."

The search system returns search results as a list of hyperlinks, which are simply the document headers: "Budget Code", "Average Monthly Wages in the Russian Federation", "Minimum Pension in the Russian Federation", and other documents.

The next step is to work with the list of documents in the Search Results window. The required document is highlighted and viewed in the Preview information window. The final stage is sending the found information to the external text editor Microsoft Word for further use.

The use of the developed software package supporting the teaching of synthetic disciplines in teaching allowed to intensify the learning process [4].

The organization of a high-quality educational process, the visibility and accessibility of information and educational, reference, and legislative materials are the main advantages of the developed software package of subsystems. Instrumental technologies create favorable conditions for the efficiency and effectiveness of the educational process [5].

The modified method of developing electronic textbooks allows teachers with a low computer literacy to take an active part in the development of an electronic course [6]. An electronic textbook is a programmethodical complex containing information on a specific academic subject, allowing one to master this course independently or with the help of a teacher, relying on the normative base. The peculiarity of this software package is the integration of knowledge in various subject areas. The base of the reference-legal subsystem is universal, it is possible to include/delete necessary knowledge and information in it. The test subsystem provides objective information about students' possession of certain knowledge. It can be concluded that the pedagogical innovative technology presented in the article [7] allows not only to provide a qualitatively new level of the educational process, but also positively affects the quality of management of the educational activities of the university in the context of increasing its effectiveness [8].

\section{Conclusion}

The developed software package can be effectively used in various universities, including in the study of disciplines that require constant updating of information.

It is revealed that the teaching of some disciplines without taking into account regulatory factors significantly degrades the quality of the educational process. It is necessary to highlight the problem associated with the need to refer to the current editions of regulatory documents in the process of their development. The existing software (electronic textbooks, training systems, electronic textbooks, electronic 
simulators) do not allow to fully organize the educational process using exactly the current regulatory documents. To improve the quality of education, especially in relation to synthetic disciplines, it is proposed to use the developed "Software Package for the Support of Teaching Synthetic Disciplines".

The introduction of active forms and methods of teaching develops students' skills in practical work with reference and legal documents. The complex allows a student to get a systematic idea of the subject, use analytical capabilities, read comments, and practice extensively.

Studies on solving practical problems using the Training system and comparing solutions of these problems with the source text show the effectiveness of the Training system: high search speed, completeness of information, relevance and accuracy of legal and reference information issued to a student, which confirms its importance and necessity. In carrying out practical tasks without a training system, students had many difficulties with the scatter of legal documents.

In conclusion, it should be noted that the software package and the implementation of the proposed methodology for teaching synthetic disciplines open up a wide range of opportunities for subject teachers.

The "Software package for the support of teaching economic synthetic disciplines" is registered with the Federal Service for Intellectual Property. The certificate of the state registration of computer programs No. 2017613028 of March 07, 2017.

\section{Acknowledgments}

The article was prepared as part of a program of initiative research on the topic "Intellectualization of information systems and technological processes in the field of education" (Project No. 2.9402.2017/БЧ).

\section{References}

[1] Vasyutina, T. L., \& Stakhno, R. E. (2016). The use of modern information technology in training. Problems of modern science and education, 7, 49, pp. 52-54.

[2] Kuhn, Thomas S., (1970). The Structure of Scientific Revolutions, 2nd enl. ed. Chicago, US: University of Chicago Press.

[3] Shikhnabieva, T., \& Beshenkov, S. (2016). Intelligent system of training and control of knowledge, based on adaptive semantic models. In Smart Education and e-Learning 2016 (pp. 595-603). Cham, Germany: Springer.

[4] Khachaturova, S. S. (2016). Hypertext integration of the reference legal subsystem in the educational environment. Scientific Review: Economics, 2, pp. 200-205.

[5] Tereshonok, T. V., Aisner, L. Y., \& Bogdan, O.V. (2016). Pedagogical technologies in modern education. Successes of Modern Science, 3(1), pp. 30-32.

[6] Gushchin, A. V. (2014). The concept and value of information technology support in the development of e-learning of higher pedagogical education. Basic Research, 12(9), pp. 2003-8.

[7] Robert, I. V., et al., (2017). Forecast of the Development of Education Informatization. Revista Espacios, 38, 40.

[8] Tikhonova, V. A. (2010). The system of state management of innovative technologies in education. Modern High Technologies, 8, pp. 60-62. 